\title{
Whatsapp. Hábitos de uso y construcción de identidad visual con mensajería móvil
}

\section{Visual identity and mobile communication Whatsapp}

\author{
Francisco López-Cantos \\ Profesor del Departamento de Ciencias de la Comunicación \\ (Universitat Jaume I)
}

Fecha de recepción: 9 de diciembre de 2016

Fecha de revisión: 12 de abril de 2017

Fecha de publicación: 1 de julio de 2017

Para citar este artículo: López-Cantos, F. (2017):Whatsapp. Hábitos de uso y construcción de identidad visual con mensajería móvil, Icono 14, volumen 15 (2), pp. 70-91. doi: 10.7195/ri14.v15i2.996 


\section{ARTÍCULOS DE INVESTIGACIÓN}

\section{Resumen}

El objetivo de este trabajo es abordar las formas de uso y el impacto que está teniendo Whatsapp en la construcción de identidad visual online, la aplicación que domina el mercado de las comunicaciones móviles y se ha convertido en herramienta comunicativa habitual en nuestros días. Como metodología de trabajo utilizamos un cuestionario estratificado diseñado con el fin de evaluar los hábitos y formas de uso y, especialmente, las imágenes de perfil que se utilizan, en tanto que elemento determinante para la construcción de identidades individuales y grupales online. Como resultado de nuestra investigación, hemos encontrado sobre todo diferencias significativas en los hábitos de uso y la forma de construcción de identidad visual en Whatsapp en función del género y la edad, con menor incidencia de otras variables. Como conclusión, podemos constatar que la popularización masiva de las comunicaciones con dispositivos móviles promueve la tendencia a la gestión estratégica consciente de la identidad visual online y a la orientación grupal de los usuarios, en línea con otros trabajos recientes.

Palabras clave: Whatsapp - Identidad visual - Comunicación móvil - Redes sociales - Grupos online

\section{Abstract}

The goal of this paper is to deal with the forms of use and the impact for building online visual identity of Whatsapp, the app that dominates the market for mobile communications and has become a common communication tool in our day. As working metholodogy we process a stratified questionnaire designed in order to evaluate habits of use of a sample of Whatsapp users, and especially their images of profile, as determinant for building users online individual and group identity. As a result of our research, we found significant differences mainly by gender and age in the habits and forms of use and the visual identity management of Whatsapp. As conclusion, we can state that the mass popularization of communications with mobile devices promote, in line with other recent research works about online communication, the trend to strategic aware management of visual identity online and users group orientation.

Key Words: Whatsapp - Visual identity - Mobile communication - Social network sites SNS - Online groups 


\section{Introducción}

Estamos inmersos en unos tiempos en los que la presencia y uso de las tecnologías de la comunicación en nuestras actividades cotidianas forma parte indisoluble de nuestra propia existencia ${ }^{1}$, que construimos como producto complejo de distintos tipos de interacción simbólica. Muchas veces utilizando tecnologías de comunicación online, otras en encuentros presenciales, y en general combinando ambos tipos de interacción. En este sentido, nuestra identidad se conforma como resultado de un proceso simbólico complejo y dinámico (Goffman, 1959; Mead, 1932), en el que utilizamos el lenguaje y la comunicación con carácter performativo (Austin, 1962), y en tensa transformación (Castells, 1997), como resultado de un largo proceso histórico (vid. Habermas, 1984; Lypovetsky, 1986; Lyotard, 1987; Debord, 1999; Baunman, 2013).

En este entorno, en que convergen diferentes corrientes de pensamiento y teorías ya clásicas sobre análisis de redes formuladas desde la antropología, la psicología, la sociología o las matemáticas (vid. Lozares, 1991), y en la estela de investigaciones recientes sobre las conductas y las nuevas formas de relación en red y las comunicaciones móviles (García y Rosado, 2012; Martínez-Rodrigo y Sánchez-Martín, 2015; Rubio-Romero y Perlado, 2015), nos resulta de especial interés la extensión de uso y la ubicuidad que ha adquirido la mensajería móvil, y especialmente Whatsapp y su incidencia en la gestión diaria de identidades personales y grupales.

Multitud de estudios apuntan la clara orientación de los individuos al grupo en búsqueda de aceptación social a partir de la construcción de una identidad que permita estabilidad y seguridad ontológica (Hogg \& Reig, 2006; Strano, 2008; Zao et al., 2008) y en un entorno como el actual, caracterizado por el elevado nivel de riesgo (Beck, 2002) y que impregna a los individuos hasta los ámbitos más intimos, la reducción de la incertidumbre y la gestión adecuada de la identidad se convierte en una cuestión crucial. En este sentido, nuestro «lugar en el mundo», o «dwelling» en palabras de Ingold (2000), es el resultado de la progresiva cohabitación en espacios virtuales online-offline en el que la gestión de la imagen personal se ha convertido en una actividad normalizada y un acto comunicativo estratégico, 


\section{3 | Francisco López-Cantos}

\section{ARTÍCULOS DE INVESTIGACIÓN}

en un esfuerzo de presentación online de rasgos identificativos que puedan definir a cada individuo como 'el mejor miembro del grupo' (Campbell, 2006). Igualmente interesante es la relación y el grado de fiabilidad o «warranty» existente entre la identidad offline y online de los usuarios (Hall et al., 2014).

Son todavía escasos los estudios específicos sobre Whatsapp, probablemente dado el rápido crecimiento que el uso de estas aplicaciones ha tenido entre los usuarios y su relativa novedad como objeto de estudio en el ámbito académico, al contrario que ocurre con Facebook, LinkedIn, Twitter, Instagram, etc. de los que se puede encontrar hoy una ya amplia bibliografía (Van Dick, 2013; Sauter, 2013; Van Zoonen, 2013, Tsay-Vogel, 2015). Algunos trabajos, en esta línea, ya han mostrado con claridad la correlación entre el aumento de la preocupación por la identidad visual con el incremento en el uso de la comunicación online y las redes sociales (Won \& Makana, 2015), las diferencias culturales existentes en los usos de las redes sociales (Rui \& Sterfanone, 2013), así como la tendencia a la consciencia explícita en su utilización estratégica (Hum, 2011; Saslow, 2012; Toma \& Hancock, 2012).

Muy recientemente, se ha abordado el estudio de Whatsapp desde el punto de vista antropológico en una investigación promovida desde el Microsoft Research Cambridge (0'Hara et al., 2014), que muestra la significativa relevancia que ha adquirido en la construcción de identidad y sentido en nuestra cotidianeidad, concluyendo que en Whatsapp «It is togetherness and intimacy enacted through small, continuous traces of narrative, of tellings and tidbits, noticings and thoughts, shared images and lingering pauses. This friendship has a history and an ongoing trajectory into the future».

En este sentido, es especialmente significativo el uso de la imagen que se utiliza como perfil, en tanto que sirve para la identificación primaria del usuario y se adjunta en cada uno de los mensajes, incluso lo referencia aunque el usuario no esté online, y debido a su mayor pregnancia cognitiva por interpretarse de manera inmediata desde lo que recientemente se ha venido denominando como «sistema cognitivo 1» (Kahneman, 2011). 
En este trabajo, por nuestra parte, analizamos los hábitos de uso $\mathrm{y}$, especialmente, las pautas de construcción de identidad visual en Whatsapp, entendiendo que los resultados y conclusiones obtenidas pueden hacerse extensivos a otras aplicaciones de mensajería móvil similares.

\section{Materiales y metodología}

Se conoce el tráfico de datos que Whatsapp supone en el conjunto de las redes móviles (Fladino, Schiavone \& Casas, 2014), que se calcula en alrededor de 64 billones de mensajes diarios, siendo el $40 \%$ mensajes de vídeo, y se calcula que se intercambian unos 700 millones fotos al día. Se han analizado las diferencias funcionales respecto a la clásica mensajería SMS (Church \& Oliveira, 2013), concluyendo la incidencia que tiene en el éxito y popularización de Whatsapp la posibilidad de creación de grupos y su facilidad de uso y gratuidad.

Respecto los hábitos de uso, se ha elaborado un reciente estudio (Montag et al., 2015) en el que se utiliza una aplicación que se instala en el móvil para monitorizar la actividad de los usuarios, y se concluye que el uso de Whatsapp es mayor en mujeres que hombres y mayor en jóvenes que adultos, y supone el 19,83\% (32.11 minutos al día) del total de uso del móvil, muy por encima del uso de Facebook (9,38\% y 15.19 minutos por día), y a mucha distancia del resto de aplicaciones de redes sociales y mensajería móvil.

Para nuestro estudio hemos utilizado un cuestionario (Anexo I) que, después de un proceso de pre-test y reelaboración, se ha puesto a disposición pública online ${ }^{2}$ para su cumplimentación anónima.

Se ha conformado la muestra de análisis estratificada con individuos agrupados por sexo y edad, en la tradición de los estudios ya citados que muestran que son las variables sociológicas que resultan en diferencias más significativas. Se ha seleccionado a dos representantes de cada sexo en tres rangos de edad $(20,30 \mathrm{y}$ 40 años), y a cada uno de ellos se le ha pedido que requiera a sus cinco contactos más frecuentes de Whatsapp que cumplimenten también la encuesta. A cada encuestado se le solicita que analice la imagen de perfil de sus diez contactos más 


\section{ARTÍCULOS DE INVESTIGACIÓN}

frecuentes de Whatsapp y la propia. De este modo, se esperaba obtener datos de alrededor de 60 personas y 660 de imágenes de perfil.

Además de los datos sociológicos básicos de los usuarios, hemos preguntado sobre algunos aspectos relativos a sus rasgos de personalidad, utilizando una escala de Lickert y con ítems elaborados a partir de los «BigFive Personality Test» desarrollados en la Universidad de Berkeley (John, Naumman \& Soto, 2008), y también hemos incluido cuestiones sobre hábitos, frecuencia y forma de uso de Whatsapp y otras aplicaciones móviles.

Para el análisis de la imagen de perfil hemos establecido un conjunto de categorías en línea con otros trabajos de investigación similares (Yen-Chun et al., 2015; Farquar, 2012; Siibak, 2009), que han sido valoradas por los usuarios en cuanto a adecuación.

\section{Resultados}

Después de la recogida de datos se ha obtenido un total de 54 encuestas y una vez realizado el proceso de revisión se han desechado los registros incompletos, quedando finalmente la muestra de estudio en 48 casos y un total de 528 imágenes.

\subsection{Marco sociológico}

De la muestra de análisis un $32,43 \%$ son hombres y un $67,57 \%$ mujeres, con una edad media de 30,83 y 32,32 años, respectivamente. Entre los encuestados el grupo más numeroso entre los hombres está en la franja 30-39 años, 16,22\% del total de individuos en la muestra, mientras que en las mujeres en el rango 20-29 años, $24,32 \%$.

\begin{tabular}{|l|c|c|c|}
\hline \multicolumn{2}{|c|}{ Marco Sociológico } & Mujeres & Hombres \\
\hline \multirow{2}{*}{ Carácter } & Extroversión & $\mathrm{x}$ & \\
\cline { 2 - 4 } & Dinamismo & $\mathrm{x}$ & \\
\hline
\end{tabular}


ARTíCULOS DE INVESTIGACIÓN

\begin{tabular}{|c|c|c|c|}
\hline \multicolumn{2}{|c|}{ Marco Sociológico } & Mujeres & Hombres \\
\hline \multirow{4}{*}{ Carácter } & Sociabilidad & $x$ & \\
\hline & Independencia & $x$ & \\
\hline & Impulsividad & $x$ & \\
\hline & Liderazgo & & $x$ \\
\hline \multirow{2}{*}{ Área relacional } & Amigos & $x$ & \\
\hline & Trabajo & & $x$ \\
\hline \multirow{3}{*}{ Situación } & Pareja & $x$ & \\
\hline & Trabajo & & $x$ \\
\hline & Dependientes & $x$ & \\
\hline \multirow{3}{*}{ Perspectivas } & Amistades & $x$ & \\
\hline & Familia & $x$ & \\
\hline & Trabajo & & $x$ \\
\hline \multirow{2}{*}{$\begin{array}{l}\text { Satisfacción } \\
\text { General }\end{array}$} & $<40$ & $x$ & \\
\hline & $>40$ & & $x$ \\
\hline
\end{tabular}

Tabla 1: Marco sociológico

Las mujeres se perciben en promedio (sobre 5) a sí mismas en general y frente a los hombres como más extrovertidas $(3,36 / 3,16)$, dinámicas $(3,40 / 3,08)$, sociables $(3,88 / 3,58)$ y más independientes $(3,92 / 3,33)$, y también mucho más impulsivas $(3,08 / 2,08)$. Los hombres por su parte, y como puede ser esperable y en línea con los múltiples estudios de género al respecto, muestran mayor inclinación al liderazgo $(3,00 / 2,56)$. Hay mayores diferencias de género en este sentido en los rangos de edad 21-30 y 41-49, y son especialmente significativas a partir de los 40 años en cuanto a sociabilidad $(4,10 / 3,00)$ e independencia $(3,40 / 2,00)$, mientras que en la franja 31-39 las cifras en general son similares para ambos sexos. Por edades se observa diferencia positiva en cuanto a dinamismo $(\mathrm{r}=1,58)$ y negativa en sociabilidad $(\mathrm{r}=-0,6)$.

Las mujeres frecuentan más que los hombres las áreas relacionales de los amigos $(3,96 / 3,08)$. En cuanto a familia, pareja y grupos de ocio ambos sexos se interesan de manera similar, así como por las relaciones con compañeros de trabajo, aunque en este caso los hombres son más activos en algunas épocas, especialmente entre 


\section{7 | Francisco López-Cantos}

\section{ARTÍCULOS DE INVESTIGACIÓN}

los 21-30 años $(2,66 / 1,66)$ y a partir de los $40(4,00 / 3,22)$. En general, hay una tendencia en las mujeres a interesarse por todas las áreas excepto en el ámbito laboral. Se ha detectado también una fuerte covarianza entre la edad y las áreas de relación preferidas, especialmente en lo relativo a los amigos $(\mathrm{r}=-5,59)$ y trabajo $(\mathrm{r}=6,59)$, siendo reseñable también en cuanto a la familia $(\mathrm{r}=2,12)$.

Aunque las mujeres mantienen algo más de estabilidad en sus relaciones (2,4 de promedio) frente a los hombres (sólo 2), en ambos sexos la mayoría no tiene relación o es poco estable (2,27 en una escala de 5). La mayor inestabilidad entre los hombres se da en el rango 20-29, sólo 0,66, mientras que en las mujeres se da mayor estabilidad que en los hombres en sus relaciones en la franja 30-39 aunque la diferencia es poca y, en todo caso sin que sea muy elevada la cifra, sólo 3 sobre 5 .

La poca estabilidad laboral es común y sólo llega a 3 sobre 5 de promedio en el caso de los hombres, mientras que en las mujeres la situación es peor y está en 2,72. Entre quienes han finalizado bachiller o un ciclo formativo superior, un $18,92 \%$, se da mayor estabilidad laboral, con un promedio de 4,42 , cifra sensiblemente inferior, 2,33, para quienes sólo tienen certificado de secundaria, un 8,11\% del total. La formación universitaria es mayoritaria, el 72,97\%, y alrededor del 30\% del total todavía está en formación, y tal como indican los datos la mayor estabilidad laboral se da a partir de los 30 años, siendo mayor en los hombres que en las mujeres, 3,33 frente a 2,60 de promedio, y se incrementa a partir de los 40 años, aunque con resultados desiguales por género también, 5 en los hombres frente a 4,55 en las mujeres.

En algunos casos a la inestabilidad laboral se le añade la dificultad de tener a cargo personas dependientes, pues un $24,32 \%$ del total tiene hijos bajo su responsabilidad, entre los cuales sólo en el $2,70 \%$ está a cargo de los hombres frente al $21,62 \%$ restante del que se hacen cargo las mujeres. Cierto número de hombres se responsabiliza de sus padres y presumiblemente convive con ellos, un 5,41\% de la muestra total, algo que no ocurre en ningún caso en las mujeres que se hacen cargo y conviven con los hijos. 
Entre los propósitos de las mujeres frente a los hombres destaca sobre todo el interés por el fomento futuro de manera muy clara de las amistades $(3,52 / 2,83)$, y después las relaciones familiares $(3,04 / 2,41)$, y en menor medida las de pareja $(2,56 / 2,00)$. En los hombres destaca el interés por fomentar las relaciones en el trabajo $(3,00 / 2,64)$ en todas las franjas de edad y especialmente a partir de los 30 años $(4,00 / 3,00)$ y los 40 años $(3,00 / 1,88)$. En todo caso, y en general, los propósitos de fomento futuro tienden a consolidar las áreas relacionales ya frecuentadas, y sólo se observa una fuerte covarianza negativa en relación al fomento de las amistades $(\mathrm{r}=-3,05)$ y una notoria preocupación, razonable por otro lado, por fomentar las áreas relacionales en el trabajo $(\mathrm{r}=-3,90)$. Es destacable también la estrecha relación entre el incremento de la edad y el interés por fomentar la pareja o lograrla ( $\mathrm{r}=3.06)$ por encima del resto de áreas relacionales y a mucha distancia del fomento de la amistad y el trabajo.

El grado de satisfacción general está en un promedio de 4,75 sobre 7. A nivel general las mujeres se muestran más satisfechas hasta los 40 años que los hombres, 5,11 en la franja 21-30 y 4,44 en el grupo de edad 31-40 frente a 4,66 y 4,61, mientras que a partir de los 40 años, aunque mejora un poco respecto a la década anterior y se sitúa en 4,88 , el grado de satisfacción de las mujeres cae por debajo del de los hombres, que se sitúa por encima de 5 .

En el conjunto de los encuestados se dan ligeras variaciones en el grado de satisfacción en función de si se frecuenta el área de relación laboral $(\mathrm{r}=0,67)$ y los amigos $(\mathrm{r}=0,16)$, o si se participa mayormente en grupos de ocio/actividades $(\mathrm{r}=-0,34)$ y la familia $(\mathrm{r}=-0,32)$, y con el fomento de su relación o encontrar pareja $(\mathrm{r}=0,20)$.

\subsection{Uso de Whatsapp y otras aplicaciones móviles}

La mayor parte de los encuestados utiliza Whatsapp con una frecuencia inferior a las 2 horas (13,51\% cada 15 minutos, 18,92\% cada 30 minutos, 21,62\% cada hora e igual cifra cada dos horas), y sólo el 16,22\% del total lo utiliza un máximo de tres veces al día de manera habitual. 


\section{ARTÍCULOS DE INVESTIGACIÓN}

\begin{tabular}{|c|c|}
\hline \multicolumn{2}{|c|}{ Uso Whatsapp y otros } \\
\hline Frecuencia & $<2$ hs \\
\hline Franja & Tarde/Noche (jóvenes) \\
\hline Lugar & Habitación/Coche \\
\hline Tipo Uso & Breve/Conversacional (mujeres) \\
\hline Facebook & $<1$ día \\
\hline Otros usos móvil & Twiter \\
& Otras mensajería \\
& Llamadas telefóno \\
\hline
\end{tabular}

Tabla 2: Uso de Whatsapp

El 78,38\% de los encuestados utiliza además Facebook, frente a sólo el 18,92 de Google+, y un 32,43\% utiliza la popular red social al menos una vez al día. En todo caso, el 45,95\% usa múltiples aplicaciones en el móvil de redes y mensajería, entre ellos Twitter $(32,43 \%)$, y otros programas de mensajería móvil de manera puntual, el 35,14\%, y del total de los encuestados el 27,03\% utiliza habitualmente videollamadas. Sólo hay un $13,51 \%$ del total de los usuarios que no utiliza más que el correo electrónico en el móvil y ninguna otra aplicación de redes o mensajería, además de Whatsapp. Alrededor del $65 \%$ realiza llamadas telefónicas diariamente. El resto de aplicaciones similares no tienen un uso significativo entre los encuestados.

En general, es mayor el uso de Whatsapp por las tardes, noches y antes de dor$\operatorname{mir}(3,40,3,21$ y 3,10 de promedio), en menor medida al despertar $(2,83)$ y decae mucho en la madrugada $(1,02)$. Al despertar y por las mañanas es mayor en las mujeres frente a los hombres $(3,04 / 2,41$ y 2,76/1,75), y también en la madrugada $(1,12 / 0,83)$. Se ha detectado una significativa mayor intensidad de uso a menor edad, sobre todo en las noches $(\mathrm{r}=-7,75)$ y después de cenar $(\mathrm{r}=-9,19)$, y sólo ligeramente positiva en las tardes $(\mathrm{r}=1,17)$. Entre las franjas de edad de 21-30 años se utiliza más en la noche y la madrugada (4,00 y 1,33 de promedio en intensidad de uso), mientras que en el grupo de 30-39 años el mayor uso se da a primera hora de la mañana $(3,09)$. Existe también cierta relación entre el grado de estabilidad 
sentimental y el uso por las mañanas $(\mathrm{r}=0,58)$ y por las noches $(\mathrm{r}=-0,70)$, e igualmente con la situación laboral a mediodía $(\mathrm{r}=0,40)$.

En todo caso, el teléfono móvil lo utiliza de manera habitual desde la cama el 81,08\% de los encuestados antes y después de dormir, siendo en las mujeres mucho más significativa esta modalidad de uso, 73,33\% frente alrededor del 50\% en los hombres. Por otro lado, el 70\% de los usuarios de móvil en la franja de edad de 41-50 lo utiliza conduciendo, mientras que sólo alrededor del 25\% entre quienes son menores de 40 años.

En general, la forma de uso más común es el mero contacto o intercambio breve de información (4,27 de promedio), aunque también se usa de manera intensiva con fines conversacionales $(3,27)$, muy por encima de los meramente informativos o logísticos $(2,27)$ o los profesionales $(2,05)$. Ambos sexos realizan un uso parecido, excepto en el ámbito conversacional en el que destacan significativamente la mujeres frente a los hombres $(3,48 / 2,83)$, especialmente en la franja $21-30$ $(4,22 / 2,66)$, aunque la diferencia se reduce algo en el grupo $31-40(3,80 / 2,66)$ y en el 41-50 donde incluso es superada ligeramente por los hombres $(3,80 / 4,00)$. El uso para citas / sexting no es significativo en ninguno de los dos sexos (1,10 de promedio sobre 5). Por edades se detecta diferencias en cuanto a los usos informativos / logísticos $(r=5,23)$ y los conversacionales $(r=-4,01)$.

\subsection{Contactos más frecuentes}

En general, ambos sexos tienden a relacionarse más con su propio género (hombres $r=0,20$ y mujeres $r=0,25)$, y existen ciertas diferencias por grupos de edad en cuanto a las edades de los contactos frecuentes. En la franja 21-30 ambos sexos suelen frecuentar gente cercana a los 20 años de manera muy clara $(r=-12,62)$, mientras que el grupo de 31-40 es más proclive a relacionarse con gente de la franja superior de la década $(\mathrm{r}=7,93)$, y este fenómeno de ampliación del rango de edades que se frecuenta todavía se incrementa más en la franja 41-50 (r=9,79).

Contactos Frecuentes Mismo género / Amigos / Grupos Similar edad / Encuentros offline 


\section{1 | Francisco López-Cantos}

\section{ARTÍCULOS DE INVESTIGACIÓN}

Los contactos más frecuentes en Whatsapp son con amigos $(57,38 \%)$, con mucha diferencia respecto a la familia $(19,03 \%)$ y los laborales $(7,95 \%)$. Dada la inestabilidad en las relaciones sentimentales o su inexistencia los contactos con la pareja son también poco significativos $(5,39 \%)$, aunque se incrementan con el grado de estabilidad sentimental $(\mathrm{r}=0,61)$ de manera simultánea a la disminución de los encuentros con los amigos $(-0,42)$. Se encuentra sobre todo una fuerte diferencia en cuanto a la edad en lo referente a los amigos $(\mathrm{r}=-8,43)$. No hay diferencias reseñables por género en las áreas de relación frecuente aunque sí se detecta una ligera correlación positiva en las mujeres con la familia $(0,23)$. También, y en general, el grado de satisfacción está ligeramente relacionado negativamente con la frecuencia con los contactos con amigos $(\mathrm{r}=-0,61)$ y positivamente con pareja $(0,12)$ y el entorno laboral $(0,02)$, aunque no son datos significativos.

El uso social de Whatsapp es evidente y los grupos que más se frecuentan están conformados por amigos (60\%), seguidos muy de lejos por los grupos de actividades $(14,28 \%)$, la familia $(13,46 \%)$ y los de carácter laboral $(12,24 \%)$. Destaca la clara diferencia por edad en cuanto a los grupos de amigos $(\mathrm{r}=-5,16)$ y es también significativa en relación a los grupos de actividades $(2,07)$. No existen diferencias reseñables por género $\mathrm{y}$, en general, muy ligeras correlaciones entre el grado de satisfacción y la pertenencia a grupos de amigos $(\mathrm{r}=0,31)$ y de actividades $(0,33)$.

La frecuencia de contactos online es mayoritariamente diaria, más de tres veces al día en un $18 \%$ de los encuestados y en el 33,55\% al menos una vez al día. La frecuencia de contacto varía con la edad, siendo entre los de menor edad más de tres veces al día $(\mathrm{r}=-022)$, habitualmente a diario entre los mas mayores $(\mathrm{r}=3,21)$, y es más puntual con el aumento de la estabilidad sentimental $(\mathrm{r}=0,39)$. No se aprecian diferencias reseñables por género, ni en cuanto al grado de satisfacción general.

Entre las otras formas de comunicación habituales con los contactos más frecuentes de Whatsapp encontramos diferencias muy importantes en relación a la edad entre quienes hacen uso de llamadas $(\mathrm{r}=14,60)$ y quienes utilizan preferentemente de manera complementaria las redes sociales $(\mathrm{r}=-10)$, sin diferencias significativas por género. Sí se ha encontrado que quienes indican un carácter más extrovertido hacen más uso de llamadas telefónicas $(r=0,42)$ y al quienes menos de redes sociales $(r=-0,37)$. 
El $24,86 \%$ de los encuestados mantiene encuentros a diario con sus contactos de Whatsapp, y el 25,67\% al menos una vez por semana, mientras que un 30,81\% sólo de manera puntual con cierta regularidad, y el $18 \%$ en muy escasas ocasiones. Los contactos puntuales se incrementan en relación a la estabilidad de la relación de pareja $(\mathrm{r}=0,76)$ y cuando hay poca estabilidad sentimental se producen ligeros incrementos en los encuentros personales al menos una vez por semana $(\mathrm{r}=-0,28)$ y con aquellos contactos en que los encuentros son muy escasos $(\mathrm{r}=-0,55)$. Hay importantes diferencias según edades, y los contactos son diarios en los más jóvenes $(\mathrm{r}=-6,11)$ y tienden a ser más espaciados entre los encuestados de más edad, sobre todo semanales $(\mathrm{r}=5,20)$, y puntuales $(\mathrm{r}=4,63)$, y hay un leve incremento de los encuentros diarios entre las mujeres $(r=0,2)$. No son significativas las covarianzas respecto al grado de satisfacción, aunque se observa una ligera tendencia a buscar los encuentros diarios cuando hay mayor insatisfacción $(r=-0,26)$.

\subsection{Identidad visual}

Del total de imágenes evaluadas ( $\mathrm{n}=498$ ), la mayoría corresponden a fotografías $(75,74 \%)$, seguidas muy de lejos por ilustraciones o abstracciones $(17,96 \%), \mathrm{y}$ hay un $6,28 \%$ de perfiles sin imagen, una cifra realmente baja. Son significativas las diferencias de edad respecto al uso de fotografías $(\mathrm{r}=-7,26)$ e ilustraciones 0 abstracciones $(\mathrm{r}=4,69)$, y algo menores entre quienes no utilizan imagen de perfil $(\mathrm{r}=2,92)$. Las mujeres tienden a incluir ligeramente más fotografías $(\mathrm{r}=-0,21)$ que los hombres $(r=0,17)$, aunque la diferencia es poco significativa. Sí se observa cierta correlación entre el carácter extrovertido y la inclusión de fotografías $(r=0,42)$ o ilustraciones y abstracciones $(\mathrm{r}=-0,37)$.

\begin{tabular}{|c|c|}
\hline \multicolumn{2}{|c|}{ Identidad Visual } \\
\hline Fotografias & Jóvenes / Mujeres \\
\hline Personas & Rostro Neutro/Jóvenes/Hombres \\
\hline Grupos & Mujeres \\
\hline Poses/Social & Jóvenes \\
\hline Actividades & Adultos \\
\hline Frecuencia renovación & > Jóvenes \\
\hline Mejor valoradas & Neutras/Familia/Pareja \\
\hline
\end{tabular}

Tabla 3: Identidad Visual 


\section{3 | Francisco López-Cantos}

\section{ARTÍCULOS DE INVESTIGACIÓN}

El 68,38\% del total de imágenes de perfil representan personas, el 15,16\% grupos y alrededor del $8 \%$ animales u objetos. Respecto a la edad, se observa una clara diferencia en cuanto a la representación de personas $(\mathrm{r}=-6,09)$ y más débil en grupos $(\mathrm{r}=-0,17)$, y significativa en cuanto a la utilización de imágenes de animales $(r=4,11)$. Los hombres tienden más a utilizar su persona como imagen de perfil $(\mathrm{r}=-0,30)$, mientras que las mujeres hacen una utilización ligeramente superior de imágenes de grupo $(\mathrm{r}=0,19)$. También está ligeramente relacionado el mayor grado de extroversión con la representación de personas $(\mathrm{r}=0,81)$ y el menor con la representación de grupo $(\mathrm{r}=-0,29)$ y animales $(\mathrm{r}=-0,23)$. Se encuentra igualmente cierta relación entre el grado de satisfacción expresado y las utilización de fotografías de grupo $(r=0,25)$.

La mayoría de las imágenes de perfil en Whatsapp muestran un rostro neutro $(25,63 \%)$, y un número algo inferior son imágenes posando de manera explícita $(19,49 \%)$. En un $15,52 \%$ de ellas aparece la pareja o familia y el 12,27\% muestran en la imagen de perfil una situación social. Le siguen las humorísticas $(9,02 \%)$ y las que recogen a los encuestados realizando actividades de ocio $(7,22 \%)$ o en lugares emblemáticos (4,33\%). Y finalmente, hay un 3,97\% de imágenes evocadoras y sólo un 2,52\% que simbolizan el apoyo a alguna causa. Se dan importantes diferencias en la imagen de perfil en función del incremento de edad, especialmente en cuanto a la utilización de imágenes realizando actividades de ocio $(r=4,54)$ y rostros neutros $(\mathrm{r}=4,44)$, seguidas por las imágenes familiares $(\mathrm{r}=3,35)$ y humorísticas $(\mathrm{r}=1,08)$; las imágenes en que se posa son más propias de los jóvenes de manera clara $(\mathrm{r}=-6,19)$, así como las que les representan en una situación social $(\mathrm{r}=-3,76)$ y en lugares emblemáticos $(\mathrm{r}=-1,51)$. No existen diferencias significativas por género aunque los hombres tienden más a elegir imágenes de perfil con rostro neutro $(\mathrm{r}=0,48)$ y las mujeres adoptan un tono ligeramente más humorístico $(\mathrm{r}=0,16)$. No hay una relación significativa del tipo de imagen de perfil elegido ni con el grado de satisfacción ni con las características personales. Sí se encuentra cierta diferencia en cuanto a las áreas de relación que se quieren fomentar y se utilizan fotografías de tipo social cuando se quiere fomentar la participación en grupos de actividad y ocio $(\mathrm{r}=0,70)$, pero de manera más notoria cuando se quiere fomentar o se busca una relación sentimental $(1,37)$. 
Las imágenes de perfil se cambian con cierta regularidad si se tiene un carácter más extrovertido $(r=0,41)$ y en acontecimientos específicos cuando los encuestados se consideran de carácter más dinámico $(0,46)$. Existen diferencias generacionales y se incrementa la rotación de imágenes con la edad cuando se dan acontecimiento específicos $(\mathrm{r}=2,99)$, mientras que entre los más jóvenes se cambian con mayor regularidad $(-4,30)$. No hay diferencias reseñables entre géneros, y los cambios diarios en las imágenes de perfil son infrecuentes.

Las imágenes que son posados están sujetas a cambios regulares $(\mathrm{r}=1,66)$ y se renuevan semanalmente en muchos casos $(\mathrm{r}=0,75)$. Cuando se cambia como resultado de un acontecimiento específico es habitual el uso de una imagen familiar 0 de pareja $(\mathrm{r}=1,68)$ o de una situación social $(\mathrm{r}=1,36)$.

En general, las imágenes mejor valoradas son las de rostro neutro $(4,12$ de promedio sobre 5) y las familiares o de pareja (4), seguidas de las humorísticas $(3,88)$ y las que representan en actividades de ocio $(3,85)$. Las poses están relativamente bien valoradas $(3,77)$ así como los lugares emblemáticos $(3,75)$, y lo son de menor agrado de los encuestados las evocadoras $(3,63)$ y las que muestran situaciones sociales (3,41 de promedio), y todavía menos las que sirven de apoyo a una causa $(2,71)$. El ratio de adecuación y fidelidad con la realidad del encuestado y sus características propias es, sin embargo, mayor en las imágenes sociales $(1,04)$ y es bajo en las fotos de poses $(0,97)$ y las de actividades $(0,87)$.

\section{Discusión y conclusiones}

Como era de esperar, los resultados de nuestro estudio muestran sobre todo, y más que cualquier otra variable analizada, diferencias significativas en función de la edad y el género, al igual que en otros trabajos recientes sobre redes sociales y comunicación online, tanto en lo relativo al uso que se hace de Whatsapp (Montag et al., 2015), como en la forma de representación de identidad visual online (Tifferet \& Vilnai-Yavetz, 2014).

No era el objetivo de este trabajo valorar el nivel de dependencia, o «nomofobia», de los encuestados de Whatsapp, en la línea que han analizado otros estudios 
(Pierce, 2009; King et al., 2013), pero sí se ha observado que se utiliza mayoritariamente con una frecuencia inferior a las 2 horas. Se han encontrado, además, importantes diferencias por edad en cuanto a su intensidad de uso, siendo mayor en los jóvenes y especialmente a partir de la hora de cenar y en la noche y madrugada. La frecuencia de contacto es mucho mayor también en los jóvenes que en los mayores, y suele ser de varias veces por día en los jóvenes y tiende a ser diaria a medida que se incrementa la edad.

Whatsapp se utiliza sobre todo para el intercambio de información y el contacto breve, y son las mujeres y sobre todo los jóvenes quienes hacen usos conversacionales más intensivos. En cuanto a las prácticas de sexting, a diferencia de otros estudios realizados entre los más jóvenes (Drouin and Ladgraff, 2012) y adultos (Weisskirch and Delevi, 2011) no se han mencionado de manera significativa entre los encuestados.

Finalmente, tal como también han concluido otras investigaciones respecto a la imagen identitaria que se pretende proyectar visualmente (Hall et. Al., 2013), hemos encontrado ciertas diferencias entre lo que se muestra y el grado de fidelidad con la realidad, tal como han expresado los encuestados. En cuanto a la incidencia de las imágenes de perfil en la construcción de identidad visual, las mejor valoradas son las de rostro neutro y las familiares o de pareja, seguidas de las humorísticas y las que representan a los usuarios en actividades de ocio. Sin embargo, las que se consideran más fieles y garantistas son las imágenes que representan situaciones sociales.

En definitiva, las conclusiones de nuestro estudio se corresponden en líneas generales con otros recientes en cuanto a las diferencias encontradas por género y edad. Se pone de manifiesto la relevancia que han adquirido las nuevas tecnologías de comunicación y las redes sociales en la construcción de identidad y se insiste en la cada vez más clara tendencia de los usuarios a promover sus actuaciones en función de su orientación social con una consciencia explícita de uso, en la misma línea que muestran los últimos trabajos al respecto (0'Hara et al., 2014; Saslow, 2012; Toma \& Hancock, 2012). 
En el entorno online los usuarios se promocionan utilizando todos los recursos disponibles con el fin de mostrarse como "el mejor miembro del grupo" (Cambpell, 2006) y, en este sentido, la adecuada gestión estratégica de la imagen de perfil es fundamental (Farquar, 2012; Siibak, 2009).

Whatsapp no es distinto a cualquier otra forma de interacción comunicativa y se utiliza funcionalmente con fines referenciales y expresivos pero su uso más habitual es de carácter fático y performativo. Y hoy Whatsapp es una herramienta comunicativa imprescindible para establecer el "lugar en que habitamos" (Ingold, 2000), y desde donde conformamos las metáforas discursivas en la praxis cotidiana (Lakoff and Johnson, 1980).

En este complejo y dinámico entorno en el que converge la interacción comunicativa online y offline, la gestión estratégica comunicativa consciente de la identidad online es una actividad común. Por ello, creemos necesario, continuar analizando las formas de construcción de identidad visual online. En especial, creemos necesario emprender trabajos específicos de investigación sobre la conformación de identidades grupales en Whatsapp y la incidencia de la imagen en los procesos de co-aprendizaje, en línea con los pioneros estudios que se están realizando al respecto (Yen-Chun et al., 2015).

\section{Notas}

[1] En septiembre de 2015, Facebook cuenta con unos 1.400 millones de usuarios, Whatsapp cerca de 1.000, y FacebookMessenger unos 700, y entre todos, propiedad de Zuckerberg, dominan el mercado mundial de redes sociales y mensajería móvil.

[2] Disponible en https://docs.google.com/forms/d/1U4arLa10YmCh86606QaPkMopRa08DBlYkCo sn3Mqyng/viewform

\section{Referencias}

Baunman, Z. \& Lyon, D. (2013). Vigilancia líquida. Barcelona: Paidós. Beck, Ulrich (2002). La sociedad del riesgo: hacia una nueva modernidad. Ediciones Paidós Ibérica. 


\section{ARTÍCULOS DE INVESTIGACIÓN}

Campbell A. (2006). The search for authenticity: an exploration of an online skinhead newsgroup. New Media and Society 8(2), 269-294. D0I: http:// dx.doi.org/10.1177/1461444806059875

Castells, M. (1997). The Power of Identity: The Information Age: Economy, Society, and Culture, Volume II. 0xford: Blackwell Publishers.

Church,K. \& De Oliveira, R. (2013). What's up with WhatsApp? Comparing Mobile Instant Messaging Behaviors with Traditional SMS. Mobile HCI 2013 Collaboration and Communication, August 30th, 2013 - Munich, Germany.

Debord, G. (1999). La sociedad del espectáculo. Valencia: Pretextos.

Drouin, M. and Ladgraff, C. (2012). Texting, sexting, and attachment in college students' romantic relationships. Computers in Human Beavior, Vol 28 (2), 444449. D0I: http://dx.doi.org/10.1016/j.chb.2011.10.015

Farquhar, L. (2012). Performing and interpreting identity through Facebook imagery. Convergence, 19 (4), 446-471. DOI: http://dx.doi. org/10.1177/1354856512459838

Fiadino, P., Sechiavone, M. \& Casas, P. (2014). Vivisecting WhatsApp through LargeScale Measurements in Mobile Networks. SIGCOMM'14, August 17-22. Chicago, IL, USA. DOI: http://dx.doi.org/10.1145/2619239.2631461.

García García, F., Rosado Millan, M. (2012). Sociocomunicative behaviors of digital natives and young people into web 2.0. Communication \& Society 25(1), 15-38. Goffman, E. (1959). The Presentation of Self in Everyday Life. New York: Anchor Books. Habermas, J. (1984). Ciencia y técnica como ideología. Madrid: Tecnos.

Hall, J., Pennington, N. \& Lueders, A. (2013). Impression management and formation on Facebook: A lens model approach. New Media \& Society, 16(6), 958-982. D0I: http://dx.doi.org/10.1177/1461444813495166

Hum, N. et al. (2011). A picture is worth a thousand words: A content analysis of Facebook profile photographs. Computers in Human Behavior, 27, 1828-1833. D0I: http://dx.doi.org/10.1016/j.chb.2011.04.003

Hogg MA, and Reid SA (2006). Social identity, self-categorization, and the communication of group norms. Communication Theory, 16, 7-30. D0I: http:// dx.doi.org/10.1111/j.1468-2885.2006.00003.x

Ingold, T. (2000). The Perception of the Environment. London: Routledge. John, 0. P., Naumann, L. P., \& Soto, C. J. (2008). Paradigm Shift to the Integrative Big-Five Trait Taxonomy: History, Measurement, and Conceptual Issues. In 0.P. 
Whatsapp. Hábitos de uso y construcción de identidad visual... $\mid 88$

ARTÍCULOS DE INVESTIGACIÓN

John, R. W. Robins \& L.A. Pervin (eds.): Handbook of personality: Theory and research, Newyork: Guilford Press, 114-158.

Kahneman, D. (2011). Thinking Fast and Slow, Allen Lane.

King et al. (2013). Nomophobia: Dependency on virtual environments or social phobia?. Computers in Human Behavior, 29, 140-144. D0I: http://dx.doi. org/10.1016/j.chb.2012.07.025

Lakoff, G. and Johnson, M. (1980). Metaphors We Live By. University of Chicago Press. Lozares, C. (1996). La teoría de las redes sociales. Papers, 48, 103-126.

Lyotard, J. (1989). La condición postmoderna. Madrid: Cátedra.

Lypovetsky, G. (1986). La era del vacío. Barcelona: Anagrama.

Mead G. (1932). Philosophy of the Present. Chicago, IL: Open Court Publishing.

Martínez-Rodrigo, E. y Sánchez-Martín, L. (2015): Cambios tecnológicos en el contexto publicitario: Comunicación y Redes Sociales Presentación, Icono 14, volumen (13), pp. 1-5. doi: 10.7195/ri14.v13i2.887

Montag et al. (2015). Smartphone usage in the 21st century: who is active on WhatsApp?. BMC Res Notes, 8:331. D0I: http://dx.doi.org/10.1186/s13104-015-1280-z

0'Hara et al. (2014). Everyday Dwelling with WhatsApp. CSCW 2014 Mobile Apps for Enhancing Connectedness, February 15-19, 2014, Baltimore, MD, USA D0I: http://dx.doi.org/10.1145/2531602.2531679

Pierce, T. (2009). Social anxiety and technology: Face-to-face communication versus technological communication among teens. Computers in Human Behavior, 25, 1367-1372. DOI: http://dx.doi.org/10.1016/j.chb.2009.06.003

Rubio-Romero, J. y Perlado Lamo de Espinosa, M. (2015): El fenómeno WhatsApp en el contexto de la comunicación personal: una aproximación a través de los jóvenes universitarios, Icono 14, volumen (13), pp. 73-94. doi: 10.7195/ri14.v13i2.818

Rui, J. \& Stefanone, M. (2013). Strategic self-presentation online: A cross-cultural study. Computers in Human Behavior, 29, 110-118. D0I: http://dx.doi. org/10.1016/j.chb.2012.07.022

Saslow, L. et al. (2012). Can You See How Happy We Are? Facebook Images and Relationship Satisfaction. Social Psychological and Personality Science, 4 (4), 411-418. D0I: http://dx.doi.org/10.1177/1948550612460059

Sauter, T. (2013). 'What's on your mind?' Writing on Facebook as a tool for self-formation. New Media \& Society, 16 (5), 823-839. D0I: http://dx.doi. org/10.1177/1461444813495160 


\section{ARTÍCULOS DE INVESTIGACIÓN}

Siibak A (2009). Constructing the self through the photo selection: visual impression management on social networking websites. Cyberpsychology, 3(1). D0I: http://dx.doi.org/10.1016/j.sbspro.2012.11.102

Strano, M. (2008). “User descriptions and interpretations of self-presentation through Facebook profile images". Cyberpsychology, 2(2).

Tifferet, S. \& Vilnai-Yavetz, I. (2014). Gender differences in Facebook selfpresentation: An international randomized study. Computers in Human Behavior, 35, 388-399. D0I: http://dx.doi.org/10.1016/j.chb.2014.03.016

Toma, L. \& Hancock, J. (2012). Looks and Lies: The Role of Physical Attractiveness in Online Dating Self-Presentation and Deception. Communication Research, 37 (3), 335-351. D0I: http://dx.doi.org/10.1177/0093650209356437

Tsay-Vogel, M. (2015). Me versus them: Third-person effects among Facebook users. New Media \& Society, 1-17. D0I: http://dx.doi.org/10.1177/1461444815573476

Van Dijck, J. (2013). 'You have one identity': performing the self on Facebook and LinkedIn. Media, Culture and Society, 35, 199-215. D0I: http://dx.doi. org/10.1177/0163443712468605

Van Zoonen, L. (2013):" From identity to identification: fixating the fragmented self", Media, Culture \& Society, 35 (1), pp. 44-51. D0I: http://dx.doi. org $/ 10.1177 / 0163443712464557$

Walther JB \& Parks MR (2002). Cues filtered out, cues filtered in: computer-mediated communication and relationships. In Knapp ML and Daly JA (eds): Handbook of Interpersonal Communication. 3rd ed. Thousand 0aks, CA: SAGE, 529-563.

Weisskirch, R. and Delevi, R. (2011). 'Sexting' and adult romantic attachment. Computers in Human Behavior, Vol 27 (5), 1697-1701. D0I: http://dx.doi. org/10.1016/j.chb.2011.02.008

Won, J. \& Makana, T. (2015). Body image 2.0: Associations between social grooming on Facebook and body image concerns. Computers in Human Behavior, 48, 331339. DOI: http://dx.doi.org/10.1016/j.chb.2015.01.009

Yen-Chun Jim Wu, Wei-Hung Chang, Chih-Hung Yuan (2015). Do Facebook profile pictures reflect user's personality?. Computers in Human Behavior, 51, 880889. DOI: http://dx.doi.org/10.1016/j.chb.2014.11.014

Zhao, S., Grasmuck, S., \& Martin, J. (2008). Identity construction on Facebook: Digital empowerment in anchored relationships. Computers in Human Behavior, 24(5), 1816-1836. D0I: http://dx.doi.org/10.1016/j.chb.2008.02.012 


\section{Anexo I. Formulario utilizado}

- Número de encuesta

- Edad

- Género

- Estado (1 a 5) (Sin relación, Relación estable)

- Trabajo (1 a 5) (Sin trabajo, Trabajo estable)

- Formación, estudiando (Sin estudios, Secundaria / Ciclo Formativo Medio, Bachiller / Ciclo Formativo Superior, Universidad

- Personas a cargo ( Hijos, Padres)

\section{Bloque 1. Características}

- Rasgos distintivos de tu carácter (valor 1 a 5) (Extroversión, Dinamismo, Liderazgo, Impulsividad, Sociabilidad, Independencia)

- Áreas relacionales que frecuentas (sólo una respuesta por columna asignando valor 1 a 5) (Familia, Amigos, Pareja, Trabajo, Grupos 0cio/Actividad)

- Áreas relacionales que tienes propósito de fomentar en el futuro (sólo una respuesta por columna asignando valor 1 a 5) (Familia, Amigos, Pareja, Trabajo, Grupos 0cio/Actividad)

- Grado de satisfacción con tu situación actual (1 a 7) (Muy insatisfactoria, Muy satisfactoria)

\section{Bloque 2. Utilización Whatsapp}

- Redes sociales y mensajería que se usan habitualmente en el móvil ( Facebook, Twitter, Facebook Messenger, Skype, Line o similar videollamadas, Gmail Hangout, Google+, Tinder, Meetic o similar para encuentros, Correo electrónico, Otros)

- Frecuencia uso mensajería instantánea y redes sociales (Whatsapp, Otros mensajería instantánea, Otros redes sociales / información, Llamadas telefónicas) (Cada 1/4 hora, 1/2 hora, 1 hora, 2 horas, 4 horas, 3 veces día, 1 vez al día, De manera puntual) 


\section{ARTÍCULOS DE INVESTIGACIÓN}

- Intensidad uso por períodos Whatsapp (sólo una respuesta valoración 1 a 5) (Al iniciar el día, Durante la mañana, A mediodía / Después de comer, Tardes, Noches / Después de cenar, Al finalizar el día, Madrugada)

- Forma de uso Whatsapp (sólo una respuesta valoración 1 a 5) (Informativo / Logístico, Contacto / Conversación breve, Conversación / Expresión / Diálogo, Uso Profesional, Encuentros / Sexting)

- Usas el móvil desde la cama o al poco de despertar o dormir? (Sí/No)

- Usas el móvil conduciendo alguna vez? (Sí/No)

\section{Bloque 3. Características 10 primeros contactos Whatsapp}

- Contactos individuales (en orden aparición lista) (Familia, Amigos, Pareja, Laboral, 0tros)

- Grupos Whatsapp (en la fila correspondiente a su lugar de aparición) (Familia, Amigos, Pareja, Laboral, Actividades)

- Género (el mayoritario en el caso de grupos, si es equilibrado no contestar)

- Grupo Edad (edad media aproximada en caso de los grupos) (<20, 21-30, 31-40, 41-50, 51-60, >60)

- Frecuencia contacto Whatsapp (+3 veces día, Diario, Puntual)

- Otra forma de contacto frecuente (al menos una vez cada 3 días) (Redes Sociales, Otros mensajería instantánea, Llamadas telefónicas)

- Frecuencia encuentros personales (Diario, Semanal, Puntual)

- Imagen de perfil (Fotografía, Ilustración / Abstracción, Sin Imagen de Perfil)

- Frecuencia con que se cambia (Diario, Semanal, Con cierta regularidad, Acontecimientos especiales)

- Imagen de perfil (Persona, Grupo, Animal, Objeto)

- Imagen de perfil (Rostro neutro, Pose, Social, Familia/Pareja, Evocación/ Romanticismo, Humor, Lugar, Actividades, Apoyo causa, Textos, Imagen Propia)

- Imagen de perfil - Valoración general (1 muy mala, 5 muy buena)

- Imagen de perfil - Adecuación a las características reales (1 nada, 5 todo)

- Comentarios adicionales 